\title{
Triangular lipodermal flaps in Wise pattern reduction mammoplasty (superomedial pedicle): A novel technique to reduce T-junction necrosis
}

\author{
Haitham H Khalil MSc MRCSEd FRCSEng MD¹, Marco Malahias MRCS MSc ${ }^{2}$, Geeta Shetty FRCS ${ }^{3}$
}

HH Khalil, M Malahias, G Shetty. Triangular lipodermal flaps in Wise pattern reduction mammoplasty (superomedial pedicle): A novel technique to reduce T-junction necrosis. Plast Surg 2016;24(3):191-194.

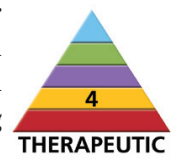

BACKGROUND: Although Wise pattern reduction mammoplasty is one of the most prevalent procedures providing satisfactory cutaneous reduction, it is at the expense of inevitable lengthier scars and wound complications, especially at the inverted $\mathrm{T}$ junction.

OBJECTIVE: To describe a novel technique providing tension-free closure at the $\mathrm{T}$ junction through performing triangular lipodermal flaps. The aim is to alleviate skin tension, thus reducing skin necrosis, dehiscence and excessive scarring at the $\mathrm{T}$ junction.

METHODS: One hundred seventy-three consecutive procedures were performed on 137 patients between 2009 and 2013. Data collected included demographics, perioperative morbidity and resected breast tissue weight. The follow-up period ranged from three to 30 months; early and late postoperative complications and patient satisfaction were recorded.

RESULTS: Superficial epidermolysis without T-junction dehiscence was experienced in eight $(4.6 \%)$ procedures while five $(2.9 \%)$ procedures developed full-thickness wound dehiscence. Ninety-four percent of patients were highly satisfied with the outcome.

CONCLUSIONS: The technique is safe, versatile and easy to execute, providing a tension-free zone and acting as internal dermal sling, thus providing better wound healing with more favourable aesthetic outcome and maintaining breast projection.

Key Words: Flaps; Lipodermal; Mammoplasty; Reduction

\author{
Des lambeaux lipodermiques triangulaires dans les \\ réductions mammaires par patron de Wise (pédicule \\ supéro-externe) : une technique novatrice pour \\ réduire la nécrose à la jonction en $\mathrm{T}$
}

HISTORIQUE : Même si la réduction mammaire par patron de Wise est l'une des interventions les plus prévalentes pour assurer une réduction cutanée satisfaisante, elle se fait aux dépens de complications plus longues et inévitables des cicatrices et des plaies, particulièrement à la jonction en T inversée.

OBJECTIF : Décrire une technique novatrice sans fermeture de tension à la jonction en $\mathrm{T}$ par lambeaux lipodermiques triangulaires. L'objectif consiste à soulager la tension cutanée, réduisant ainsi la nécrose cutanée, la déhiscence et la cicatrisation excessive à la jonction en $T$.

MÉTHODOLOGIE : Entre 2009 et 2013, 173 interventions consécutives ont été exécutées auprès de 137 patients. Les données colligées incluent la démographie, la morbidité périopératoire et le poids des tissus mammaires réséqués. La période de suivi durait de trois à 30 mois. Les complications postopératoires précoces et tardives et la satisfaction des patients ont été enregistrées.

RÉSULTATS : Huit interventions (4,6\%) se sont associées à une épidermolyse superficielle sans déhiscence de la jonction en $\mathrm{T}$, tandis que cinq $(2,9 \%)$ ont donné lieu à une déhiscence pleine épaisseur de la plaie. Ainsi, $94 \%$ des patients étaient pleinement satisfaits des résultats.

CONCLUSIONS : La technique est sécuritaire, polyvalente et facile à exécuter, assure une zone sans tension et agit comme une attelle dermique interne, ce qui entraîne une meilleure cicatrisation de la plaie, aux résultats esthétiques plus favorables, qui maintient la projection mammaire.
W se pattern reduction mammoplasty (WRM) is a commonly performed procedure for aesthetic and functional purposes, and for symmetrization procedures in patients undergoing breast reconstruction. The technique provides satisfactory cutaneous reduction in both the transverse and vertical aspect, but at the expense of inevitable lengthier scars with possible risks for cutaneous necrosis at the $\mathrm{T}$ junction. This has fueled the ongoing debate over long-versus short-scar techniques. The aesthetic outcome could vary with Wise pattern due to the extent of scarring. However, other factors should be considered including age, breast size, degree of ptosis, quality of breast skin, resected volume and comorbidities. Wound problem complications remain relatively common, as well as the tendency of the outcome to deteriorate in some cases, with loss of projection and bottoming out of the lower breast pole (1-4). T-junction wound dehiscence and infections are the most common complications encountered, with evidence of their impact on surgical outcomes rarely reported in the literature. We describe an additional modification using triangular lipodermal flaps in the WRM technique aiming to reduce dehiscence with scar formation at the T-junction and, thus, a more predictable aesthetic outcome.

\section{METHODS}

Between 2009 and 2013, 173 consecutive procedures were performed on 137 patients with a mean age of 42 years (range 19 to 73 years) by one of the authors (HK). The inclusion criteria for the reduction mammoplasty included: symptomatic benign breast hypertrophy and gigantomastia $(n=36)$; and contralateral breast symmetrization postbreast reconstruction for breast cancer $(n=101)$. Patients who were current smokers, or who had a body mass index (BMI, Quetelet's index [weight/height]) $>32 \mathrm{~kg} / \mathrm{m}^{2}$ ) and uncontrolled diabetes were excluded. The mean BMI for this cohort was $28.7 \mathrm{~kg} / \mathrm{m}^{2}$. Data collected included demographics, breast size(s), degree of ptosis, perioperative morbidity and resected breast tissue weight. The follow-up period ranged from three to 30 months (mean 14 months), in which early and late postoperative complications were recorded. The emphasis on wound healing progress, specifically at the $\mathrm{T}$ junction, was recorded and compared with previously reported data. All patients were assessed subjectively and objectively for their outcome satisfaction through a clinical questionnaire and clinical assessment. The structure of the evaluation included the following domains: scar

${ }^{1}$ Department of Oncoplastic and Reconstructive Surgery; ${ }^{2}$ Department of Oncoplastic and Reconstructive Surgery; ${ }^{3}$ Department of Breast

Oncoplasty Surgery, Good Hope Hospital, Heart of England NHS Foundation Trust, Birmingham, United Kingdom

Correspondence: Dr Haitham H Khalil, Department of Oncoplastic and Reconstructive Surgery, Good Hope Hospital, Heart of England NHS

Foundation Trust, Rectory Road, Sutton Coldfield Birmingham, West Midlands, B757RR United Kingdom.

E-mail heheaa73@yahoo.com, haitham.khalil@heartofengland.nhs.uk 


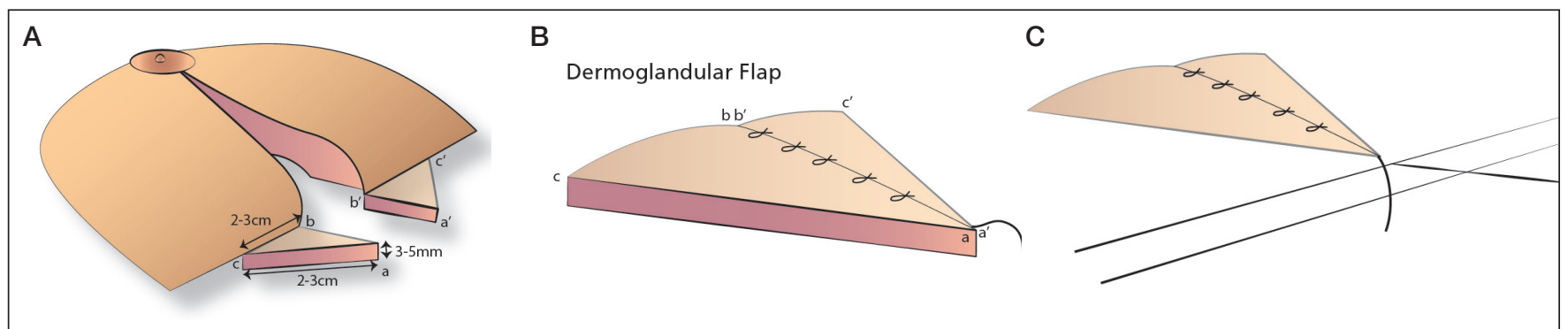

Figure 1) Illustrations demonstrating the site, size and thickness of the lipodermal flaps caudal to the each breast pillar at the breast meridian (A); Approximation of medial and lateral lipodermal flaps with interrupted sutures (B). The apical stay suture will be subsequently sutured to the musculo-aponeurotic tissue of the inframammary fold. C The lipodermal flaps secured to the musculo-aponeurotic tissue of inframammary fold approximating the vertical and horizontal axis at the breast meridian
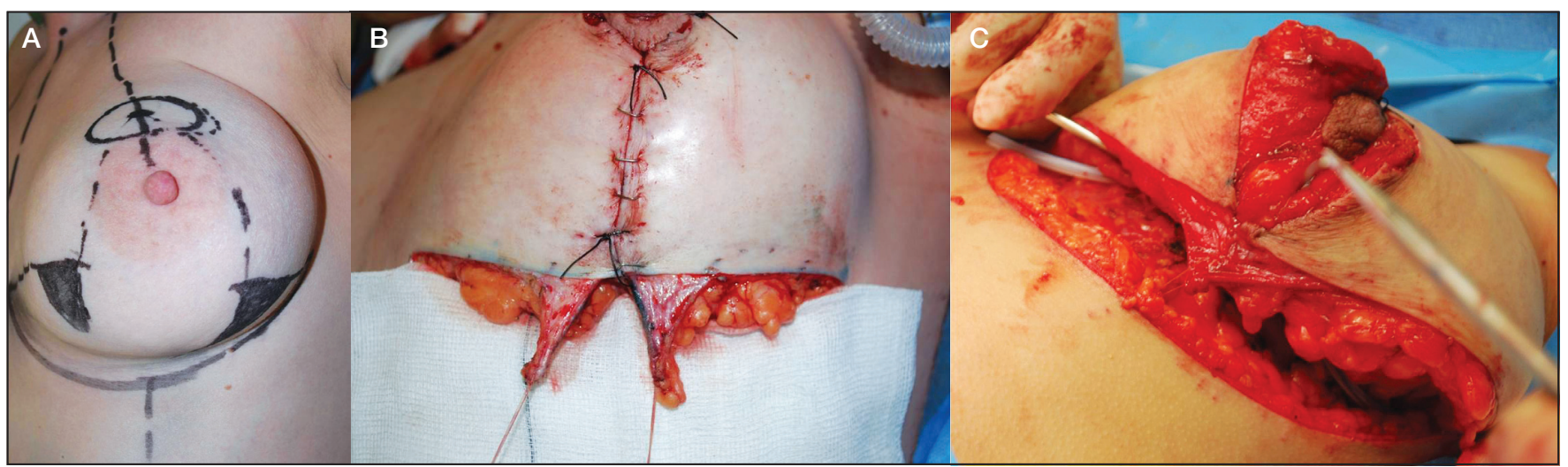

Figure 2) Intraoperative series showing: A Lipodermal flap outlined caudal to each breast pillar $3 \mathrm{~cm}$ in width and length in a patient undergoing unilateral reduction mammoplasty symmetrization. B Lipodermal flaps post de-epithelialisation after conification of the breast mould, note thickness of average 3 mm to $5 \mathrm{~mm}$. C Lipodermal flap sutured together with absorbable sutures, note the apical stay suture hinged to the musculo-aponeurotic connective tissue of inframammary fold $1 \mathrm{~cm}$ below it at the breast meridian ready to be secured

symptoms (pain, itchiness, lumpiness, and discomfort and overall appearance of the breast and its shape); consciousness of scar colour, height, width, texture and whether the scar 'caught' on clothing; and clinical evaluation of the width and height of the scar, and its texture, lumpiness, tenderness and colour.

\section{Surgical technique}

1. The standard preoperative Wise pattern marking was outlined. Subsequently, caudal to each breast pillar, a triangular zone at the breast meridian zone was marked denoting the future site of the triangular lipodermal flaps (Figures 1 and 2). The patients were anesthetized and positioned in $30^{\circ}$ semisitting position under hypotensive anesthesia. A circumareolar incision to isolate the nipple-areola complex (NAC) was performed, and followed by de-epithelialization of NAC dermoglandular flap (superomedial pedicle).

2. The two designed triangles, each measuring $2 \mathrm{~cm}$ to $3 \mathrm{~cm}$ depending on breast size, where then de-epithelialized using the knife technique and incised at their margins, leaving the base in continuity with the corresponding breast pillar. Subsequently, each triangle was dissected from the underlying breast parenchyma with a thickness of $3 \mathrm{~cm}$ to $5 \mathrm{~cm}$, being thicker toward its base to ensure good vascularization. At this stage, attention was devoted to removing most of the unnecessary subcutaneous fat to avoid future fat necrosis, which can result from tension on these flaps (Figures 1 and 2).

3. Subsequently, routine dissection and repositioning of the NAC dermoglandular flap followed by resection of excess cutaneous and fibroglandular glandular was performed. The conification of the new breast mound was achieved by suturing the medial and lateral breast pillars together, which substantially approximated the two lipodermal flaps. Absorbable sutures were used to suture the two flaps together. Their apex was then sutured to the musculoaponeurotic layer of inframammary fold (IMF) at the breast meridian $1 \mathrm{~cm}$ below the IMF. This enabled the transfer of most of the tension to the deeper plane rather than the cutaneous plane, providing a tension-free zone at the cutaneous $\mathrm{T}$ junction (Figures 1 and 2). Insertion of suction drains $(24 \mathrm{~h})$ followed by two-layer closure was performed. However, in the final 18 months of the study $(\mathrm{n}=33$ procedures), drainless reduction mammoplasty was implemented with no repercussions on overall wound healing results. In fact, when compared with patients who had drains, it was, understandably, more comfortable. Subsequently, a sports bra was applied immediately and continued for three weeks.

\section{RESULTS}

The weight of resected unilateral breast tissues ranged between $180 \mathrm{~g}$ and $1680 \mathrm{~g}$ (mean $764 \mathrm{~g}$ ). In eight (4.6\%) procedures, superficial epidermolysis was experienced at the $\mathrm{T}$ junction; these were managed conservatively with topical antibiotic and complete re-epithelization was achieved. Full-thickness wound dehiscence developed in five $(2.9 \%)$ procedures, among them one patient was diabetic and another was on long-term steroid injection for rheumatoid arthritis. The presence of comorbidity in this cohort was statistically insignificant in relation to T-junction complications. Ten of these complicated T-junction procedures occurred in resected breast tissue $>764 \mathrm{~g}(\mathrm{P}=0.0733$ [Fisher's exact test]), which was statistically not significant. Nine occurred in patients with a BMI $>28.7 \mathrm{~kg} / \mathrm{m}^{2}$, which was statistically significant $(\mathrm{P}=0.0387)$. The scar width ranged between $2 \mathrm{~mm}$ and $11 \mathrm{~mm}$ (mean $3 \mathrm{~mm}$ ). There was no statistical difference whether the procedure was performed as a symmetrization for previous breast cancer treatment versus benign breast hypertrophy $(\mathrm{P}=0.492)$. Subjective and objective clinical evaluation revealed that $94 \%$ of patients graded their outcome as highly satisfactory. 

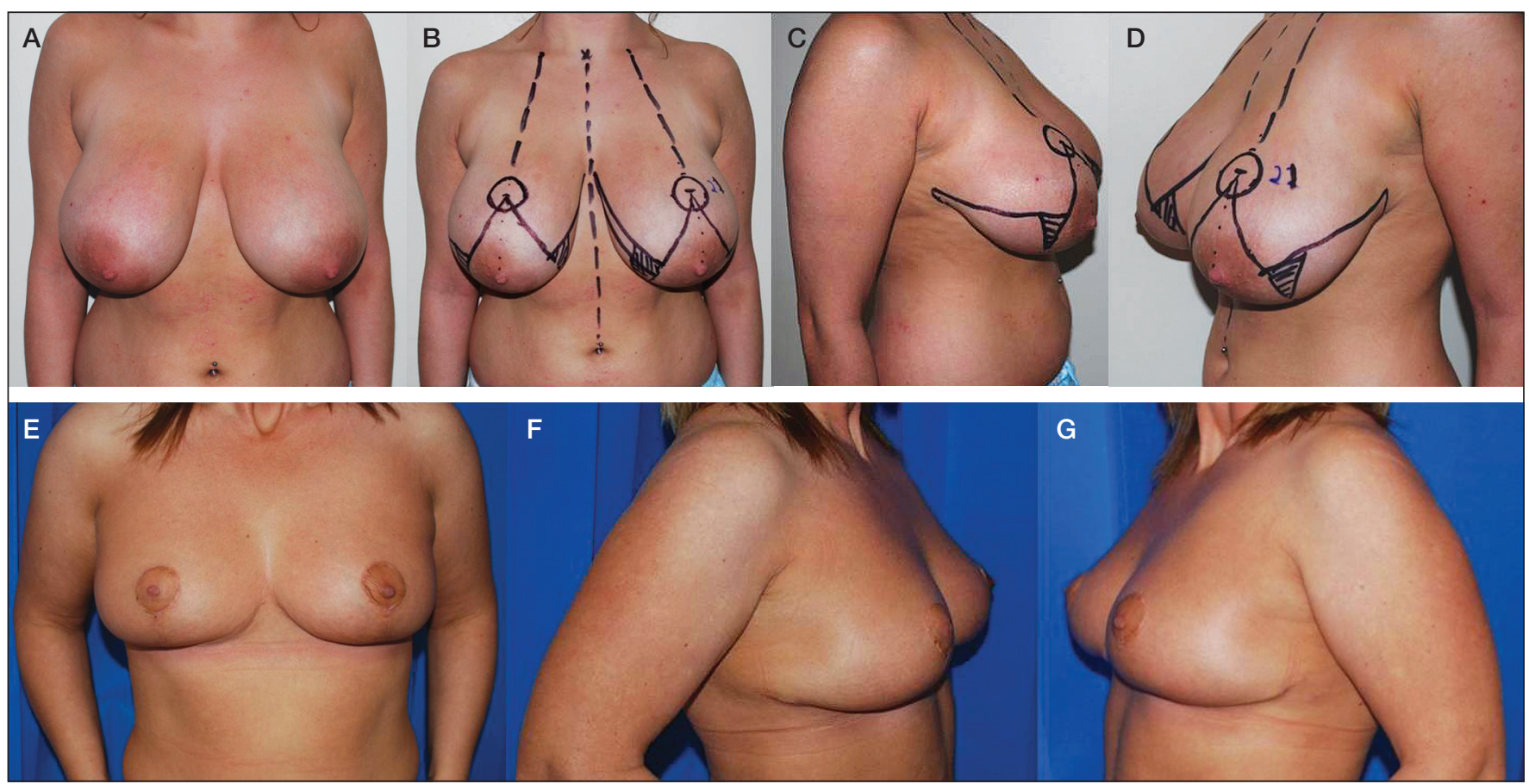

Figure 3) Case 1, A to D Preoperative anterior and oblique photos of patient with severe benign breast hypertrophy and ptosis showing preoperative markings of the Wise pattern mammoplasty and lipodermal flaps. A total of $1450 \mathrm{~g}$ of breast tissue resected. E to G Follow-up anterior and oblique views at 12 months

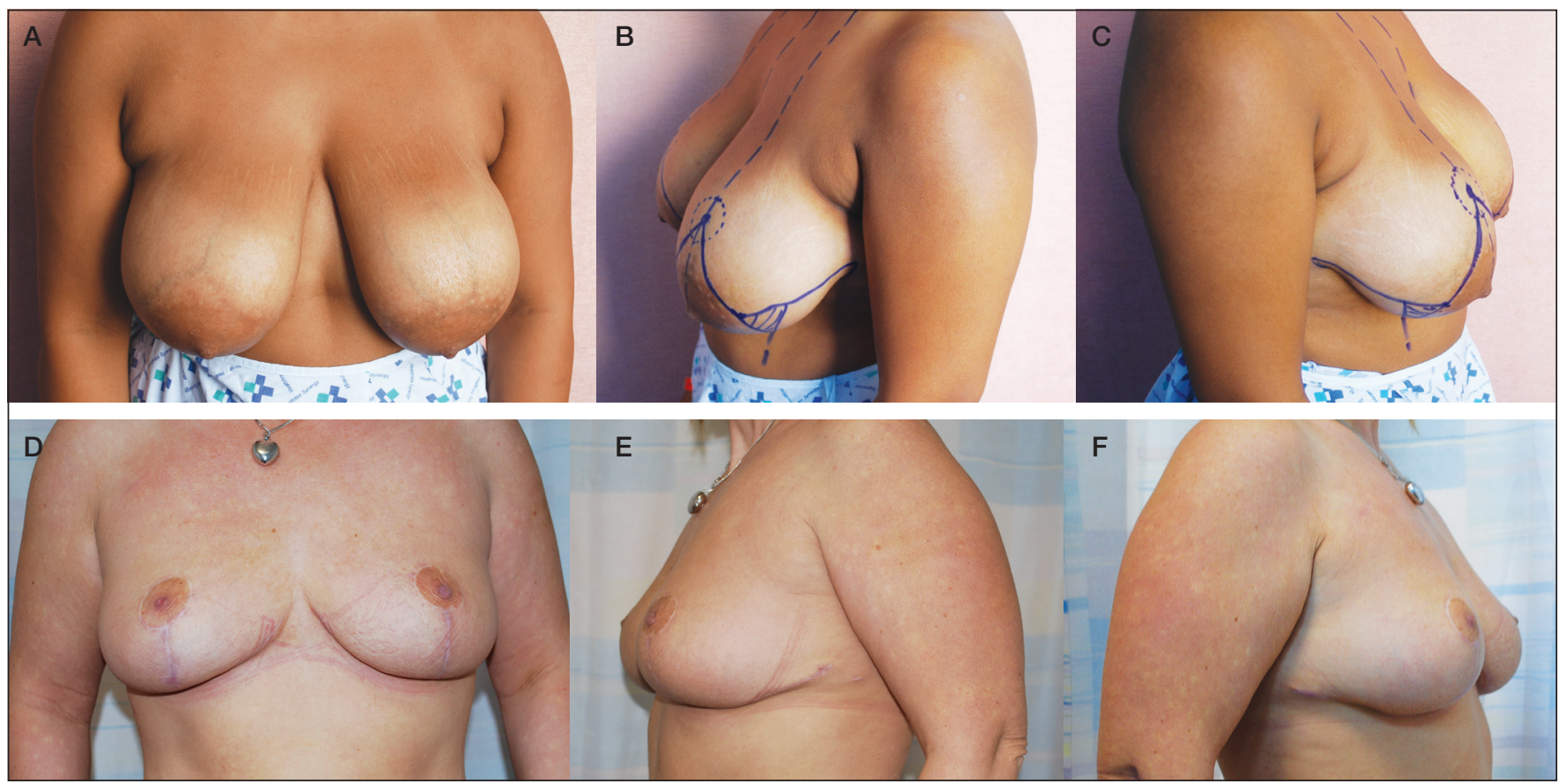

Figure 4) Case 2, A to C Preoperative anterior and oblique photographs of a patient with severe benign breast hypertrophy and ptosis showing preoperative markings of the Wise pattern mammoplasty and lipodermal flaps in oblique views. D to F A total of $1550 \mathrm{~g}$ of breast tissue was resected. Follow-up anterior and oblique views at 12 months

\section{DISCUSSION}

Patient satisfaction after mammoplasty is directly related to the patient's subjective perception of scar quality. In most of the unsatisfied patients, the scar is aesthetically unacceptable. Numerous modifications have been implemented in various reduction mammoplasty techniques to preserve the function and the geometry of the breast. Techniques with inverted $\mathrm{T}$ scar yield a satisfactory cutaneous reduction at both the transverse and vertical aspects but at expense of poor scar quality due to possible risks for cutaneous necrosis at the $T$ junction and loss of breast projection. In the literature, the complication rate varies between $14 \%$ and $52 \%$, with wound healing complications representing the most common (5-9). Stevens et al (5) and Zoumaras et al (6) specifically highlighted overall complications with T-junction breakdown as $10 \%$ and $39 \%$, respectively. Risk factors, including smoking, diabetes mellitus, high BMI, preoperative breast volume and skin quality, should always be taken into consideration due to the increase risk for wound complications (2,9-11). There has always been an inconsistent relationship between obesity and complications, which may be attributed to the arbitrary definitions used to define obesity including weight, kg over ideal body weight, percent over ideal 


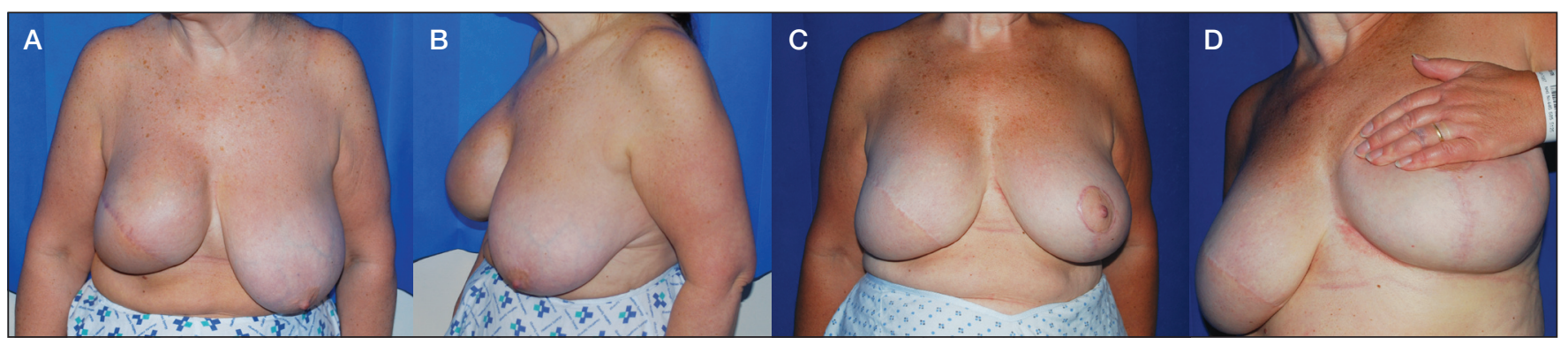

Figure 5) Case 3, A and B Preoperative anterior and oblique view of a patient (body mass index $32 \mathrm{~kg} / \mathrm{m}^{2}$ ) with previous right breast reconstruction with lattissmus dorsi and implant for breast cancer and contralateral benign breast hypertrophy with severe ptosis. C Anterior view post left reduction mammoplasty symmetrization procedure with excellent shape and symmetry at 18 months (340 $\mathrm{g}$ of breast tissue resected). D Close up of the $\mathrm{T}$ junction healed with primary intention

body weight, BMI and body surface area. Cunningham et al (9) did not report any association between BMI and an increased incidence of complications. This finding was in contrast to Setala et al (7), who noted a significant increase in overall complication rate (52\%), with the most common being delayed healing with superficial infection $(26 \%)$ and skin necrosis or wound dehiscence (18\%). Zubowski et al (12) reported an increase of $>5 \%$ in obese patients. This was consistent with our finding, which showed a statistically significant $(P=0.0387)$ increase in T-junction complication with a BMI $>28.7 \mathrm{~kg} / \mathrm{m}^{2}$. However, our overall incidence of $\mathrm{T}$-junction wound breakdown was $2.9 \%$, which is lower than what has been reported in the literature. In a prospective study, Menke et al (13) noted an increased complication rate with larger reductions. This correlated with the results of our study in which T-junction morbidity was higher in breast resections $>750 \mathrm{~g}$. Overall, this was statistically not significant because $\mathrm{T}$ junction morbidity was considerably lower when compared with other published studies due to differences in technique and adherence to selection criteria. De la Plaza et al (11) described a crossed dermal flap technique in WRM, in which two rectangular areas under each breast pillar were de-epithelized and crossed, then fixed to the IMF. They reported that $14 \%$ required further surgery to excise small folds in addition to liposuction at the extreme of the scars. Arguably, this could be due to the fact that their technique would lead to bulkiness and unevenness both at the $\mathrm{T}$ junction and along the transverse limb due to crossing of these flaps. This could have caused excess undistributed tension, which required further revisional surgeries. In contrast, the triangular lipodermal flaps do not add any bulkiness because most of the subcutaneous fat is denuded, leaving only up to $5 \mathrm{~mm}$ thickness. Once sutured, they settle in their normal resting tension-free position; therefore leading to equally distributed tension all over the transverse limb. None of our patients required further surgery to refashion the scars. One of the limitations of Plaza's technique is that the superomedial pedicle was indicated in mild/moderate hypertrophy and ptosis, while with severe ptosis and gigantomastia, they performed an inferior dermoglandular NAC. This hindered performing the crossed dermal flap safely because incision or complete transection of the base of the NAC inferior pedicle was required. We believe that this would jeopardize the vascularity of the NAC pedicle, which occurred in $2 \%$ of their patients. In our study, all patients, including those with gigantomastia, underwent the superomedial pedicle technique. That clearly did not interfere with the execution of the triangular lipodermal flap and no NAC vascular events were recorded. The main aim of the technique described is to create a tension-free zone closure at the $\mathrm{T}$ junction to avoid ischemia. This would eventually reduce subsequent wound breakdown and excessive scarring resulting from healing with secondary intention. In addition, it will act as an internal dermal sling, which helps to prevent bottoming out, avoiding loss of breast projection with excellent-quality scars.

\section{CONCLUSION}

The triangular lipodermal flap represents an additional valuable modification in the Wise pattern reduction mammoplasty technique, which is simple and versatile. It provides a cutaneous tension-free zone at the inverted $\mathrm{T}$ junction and acts as an internal dermal sling, thus providing better wound healing and maintaining breast projection with provision of optimum aesthetic results.

DISCLOSURES: The authors have no financial disclosures or conflicts of interest to declare.

\section{REFERENCES}

1. Davison SP, Mesbahi AN, Ducic I, Sarcia M, Dayan J, Spear SL. The versatility of the superomedial pedicle with various skin reduction patterns. Plast Reconstr Surg 2007;120:1466-76.

2. McCulley SJ, Schaverien MV. Superior and superomedial pedicle wise-pattern reduction mammaplasty: Maximizing cosmesis and minimizing complications. Ann Plast Surg 2009;63:128-34.

3. Cárdenas-Camarena L. Reduction mammoplasty with superolateral dermoglandular pedicle: Details of 15 years of experience. Ann Plast Surg 2009;63:255-61.

4. Mojallal A, Comparin JP, Voulliaume D, Chichery A, Papalia I, Foyatier JL. Reduction mammaplasty using superior pedicle in macromastia. Ann Chir Plast Esthet 2005;50:118-26.

5. Stevens WG, Gear AJ, Stoker DA, et al. Outpatient reduction mammaplasty: An eleven-year experience. Aesthet Surg J 2008;28:171-9.

6. Zoumaras J, Lawrence J. Inverted-T versus vertical scar breast reduction: One surgeon's 5-year experience with consecutive patients. Aesthet Surg J 2008;28:521-6.

7. Setala L, Papp A, Joukainen S, et al. Obesity and complications in breast reduction surgery: Are restrictions justified? J Plast Reconstr Aesthet Surg 2009;62:195-9.

8. Scott GR, Carson CL, Borah GL. Maximizing outcomes in breast reduction surgery: A review of 518 consecutive patients. Plast Reconstr Surg 2005;116:1633-9.

9. Cunningham BL, Gear AJ, Kerrigan CL, Collins ED. Analysis of breast reduction complications derived from the BRAVO study. Plast Reconstr Surg 2005;115:1597-604.

10. Bartsch RH, Weiss G, Kästenbauer T, et al. Crucial aspects of smoking in wound healing after breast reduction surgery. J Plast Reconstr Aesthet Surg 2007;60:1045-9.

11. De la Plaza R, De la Cruz L, Moreno C, Soto L. The crossed dermal flaps technique for breast reduction. Aesthetic Plast Surg 2004;28:383-92.

12. Zubowski R, Zins JE, Foray-Kaplon A, et al. Relationship of obesity and specimen weight to complications in reduction mammoplasty. Plast Reconstr Surg 2000;106:998-1003.

13. Menke H, Eisenmann-klein M, Olbrisch RR, Exner K. Continous quality management of breast hypertrophy by the German Association of Plastic Surgeons: A preliminary report. Ann Plast Surg 2001;46:594-8. 


\title{
Is antibiotic prophylaxis in breast augmentation necessary? A prospective study
}

\author{
E Keramidas MD EBOPRAS ${ }^{1}$, NS Lymperopoulos PhD MRCSEd ${ }^{2}$, S Rodopoulou MD EBOPRAS ${ }^{1}$
}

E Keramidas, NS Lymperopoulos, S Rodopoulou. Is antibiotic prophylaxis in breast augmentation necessary? A prospective study. Plast Surg 2016;24(3):195-198.

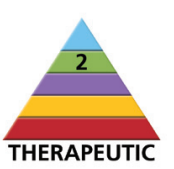

BACKGROUND: The role of prophylactic antibiotics in breast augmentation remains controversial. However, the majority of surgeons are administering antibiotics.

OBJECTIVE: To investigate the effect of antibiotic(s) use in the incidence of infection and capsular contracture following breast augmentation. METHODS: From September 2004 to November 2010, 180 patients underwent primary bilateral breast augmentation. They were prospectively divided into two equal groups: in group $A(n=90)$, no antibiotics were given and, in group B ( $\mathrm{n}=90)$, only one intravenous dose of cephalosporin was administered during the induction of general anesthesia. Preoperative data included age, body mass index, smoking status, medical history and implant volume. All operations were performed by the same surgeon using the same surgical technique and implant type. No drains were used. Operative data included operative time and estimated blood loss. Patients were evaluated for complications such as infection, hematoma and capsular contracture. The study concluded when all of the patients underwent the one-year follow-up. The Student's $t$ test was used to analyze the results.

RESULTS: All patients completed the study and both groups had similar demographic data. No differences in operative data were observed. The mean operative time was $35 \mathrm{~min}$ and the mean blood loss was found to be minimal. In group A, no implant infections were reported, while a wound infection that occurred was treated successfully with oral antibiotics. In group B, no implant or wound infection was noticed. No capsular contractures or hematomas were observed.

CONCLUSIONS: The number of patients who underwent primary breast augmentation without antibiotics $(\mathrm{n}=90)$ was insufficient to draw any definitive conclusions. However, the present prospective study demonstrated that prophylactic use of antibiotics in breast augmentation had no significant effect on infection and capsular contracture rates. Further randomized clinical trials, in combination with guidelines from aesthetic plastic surgery societies, appear to be warranted.

Key Words: Antibiotics; Breast augmentation; Implants; Infection

\section{La prophylaxie antibiotique est-elle nécessaire en cas d'augmentation mammaire? Une étude prospective}

HISTORIQUE : Le rôle de la prophylaxie antibiotique est controversé en cas d'augmentation mammaire. Toutefois, la majorité des chirurgiens en administrent.

OBJECTIF : Examiner l'effet des antibiotiques sur l'incidence d'infections et de contractures capsulaires après une augmentation mammaire.

MÉTHODOLOGIE : De septembre 2004 à novembre 2010, 180 patientes ont subi une augmentation mammaire primaire bilatérale. Prospectivement, elles ont été divisées en deux groupes égaux. Aucun antibiotique n'a été administré dans le groupe A $(n=90)$, tandis que dans le groupe $B(n=90)$, une seule dose de céphalosporine a été administrée par voie intraveineuse pendant l'induction de l'anesthésie générale. Les données préopératoires incluaient l'âge, l'indice de masse corporelle, le tabagisme, les antécédents médicaux et le volume des implants. Le même chirurgien a procédé à toutes les opérations, selon la même technique chirurgicale et à l'aide du même type d'implants. Il n'a pas utilisé de sonde. Les données opératoires incluaient la durée de l'opération et la perte de sang estimative. Les chercheurs ont évalué les patientes pour déterminer les complications telles que les infections, les hématomes et les contractures capsulaires. Ils ont mis fin à l'étude après une année de suivi auprès de toutes les patientes. Ils ont utilisé le test de Student pour analyser les résultats.

RÉSULTATS : Toutes les patientes ont terminé l'étude, et les deux groupes présentaient des données démographiques similaires. Les chercheurs n'ont observé aucune différence à l'égard des données opératoires. L'opération durait 35 minutes en moyenne, et la perte de sang moyenne était minimale. Dans le groupe A, aucune infection des implants n'a été signalée, tandis qu'une infection de la plaie a été traitée par des antibiotiques par voie orale. Dans le groupe B, aucune infection des implants ou des plaies n'a été signalée. Aucune contracture capsulaire ni hématome n'a été observé.

CONCLUSIONS : Trop peu de patientes ont subi une augmentation mammaire primaire sans prise d'antibiotiques $(n=90)$ pour en tirer des conclusions définitives. Cependant, la présente étude prospective a démontré que la prophylaxie antibiotique en cas d'augmentation mammaire n'a pas d'effet significatif sur le taux d'infections et de contractures vasculaires. D'autres essais cliniques aléatoires, combinés à des lignes directrices des sociétés de chirurgie plastique, semblent justifiés.

selection to minimize risks and the two most common complications: infection and capsular contracture. However, the infection rates in cosmetic breast augmentation have been reported to be quite low compared with other surgical procedures, with an average rate of $1 \%$ (6), the consequences of an infected implant could be devastating for the patient and the surgeon. Treatment involving potential admission to the hospital for antibiotics and implant removal could compromise patient safety and satisfaction for the most popular cosmetic surgical procedures.

Prophylactic antibiotic administration remains an area of controversy in breast augmentation. As a surgical wound, the procedure should be classified as 'clean', where no antibiotics are required; however, the use of implants appears to have made the use of either a patients must acknowledge before consenting to the procedure (4). Inevitably, surgeons have tried to optimize techniques and patient

${ }^{1}$ Kosmesis Aesthetic Plastic Surgery Centre, Athens, Greece; ${ }^{2}$ Burn and Plastic Surgery Unit, Whiston Teaching Hospital, Liverpool, United Kingdom Correspondence: Dr NS Lymperopoulos, Whiston Hospital, Department of Plastic Surgery, Warrington Road, Liverpool, England, United

Kingdom, L355DR. Telephone 01514261600, e-mail nslymperopoulos@hotmail.com 